\title{
Incidence and predictors of diabetic ketoacidosis among children with type 1 diabetes mellitus in Western Amhara Referral Hospitals, Northwestern Ethiopia, 2018: A Retrospective Follow-Up Study
}

Melkamu Siferih Zeleke

Debre Markos University

Getiye Dejenu Kibret

Debre Markos University

Tsige Gebre

Debre Markos University

Molla Yigzaw Birhanu

Debre Markos University

Cheru Tesema Leshargie ( $\square$ chertesema@gmail.com )

Debre Markos University

\section{Research article}

Keywords: Children, diabetic-ketoacidosis, incidence, predictors, retrospective follow-up, Ethiopia

Posted Date: October 10th, 2019

DOI: https://doi.org/10.21203/rs.2.15942/v1

License: (1) (1) This work is licensed under a Creative Commons Attribution 4.0 International License. Read Full License 


\section{Abstract}

Background Diabetic ketoacidosis remains a major cause of morbidity, hospitalizations and mortality in children with established type 1 diabetes mellitus. Therefore, this study aimed to determine the incidence and predictors of diabetic ketoacidosis among children with established type 1 diabetes mellitus at Western Amhara region.

Method Institution-based retrospective follow-up study was done on 393 children with established type 1 diabetes mellitus registered between September 2013 and September 2017 in Western Amhara referral hospitals. The collected data was entered into Epidata version 4.2 and further analysis were done using STATA version 14.1. Negative Binomial Poisson Regression analysis model was used.

Result The cumulative incidence and incidence density rate of diabetic ketoacidosis among children with established type 1 diabetes mellitus in western Amhara referral hospitals was $63.9 \%$ and 41.5 per 100 person-years respectively. The incidence of diabetic ketoacidosis increased with age at diagnosis [ARR:2.61, p-value<0.001], siblings only care givers [ARR:1.87, p-value <0.001], fathers only [ARR:1.51, p-value=0.004],omission of insulin (ARR:1.58, p-value $<0.001$ ), lower frequency of clinical visits [ARR:2.35, $p$-value=0.007] and baseline insulin dose $>1.2 \mathrm{u} / \mathrm{kg} /$ day [ARR:1.39, p-value=0.015], diabetic education (no) [ARR:1.52, p-value=0.011]. But the risk was decreased with baseline insulin type (Lente and regular) (ARR; 0.73, p-value =0.006), base line insulin dose $<0.6 \mathrm{u} / \mathrm{kg} /$ day (ARR: 0.5, p-value=0.034) and community health insurance membership (no membership) [ARR: 0.49, p-value $<0.001]$. In general, this study revealed that a substantial number of patients had at least one episode of diabetic ketoacidosis and a higher rate of diabetic ketoacidosis.

\section{Introduction}

In children diabetic ketoacidosis is an acute life threatening and recurrent medical emergency that requires frequent hospitalizations, treatment and monitoring for multiple metabolic abnormalities and vigilance for complications. It is the leading cause of morbidity and mortality that continued to be a major public health concern [1]. It has considerable costs to the health care systems and adds burden of costs to the patients and families [2]. Despite the improvement in the treatment and care of type 1 diabetes mellitus and the development of guidelines, diabetic ketoacidosis is still a major cause of hospitalization and the leading cause of death in children with type 1 diabetes mellitus [1, 3-7]. According to international diabetic federation's estimation, the incidence of diabetes mellitus in Ethiopian children (0-14) was 30 per 1000 populations. The mean diabetes related expenditure per a child was 29 United States Dollars [8].

Evidences revealed that the common predictors of diabetic ketoacidosis among children with type 1 Diabetes Mellitus were age at diagnosis [9-20], sex [9-12, 14-16, 18-20], lack of healthcare insurance [16, 19, 20], residence $[9,14,15,19]$, primary care giver [14, 19], insulin dose [9-12, 14, 15, 19-22], missed insulin [9], comorbidities like depression, epilepsy, bronchial asthma and down syndrome [13, 15, 21, 22], childhoodinfections [9, $15,20,23]$, lower frequency of clinical visits [11, 16, 18], omission of insulin [11, 18, 20], absence ofdiabetic education [11, 15, 19]. Moreover, protocols currently used for the management of DKA in sub-Saharan Africa were largely based on those used in developed world, which do not take into consideration co variables, associated with DKA unique to developing countries [24].

Diabetic ketoacidosis has an overall mortality between 15 and 31 per 10,000 patients, and cerebral edema (CE), which is a devastating complication, accounts for between $57 \%$ and $87 \%$ of DKA related deaths [12]. Even in developed countries, there is significantly excess mortality from ketoacidosis among children with type 1 diabetes 
mellitus [25]. The incidence of DKA varies considerably between different countries and studies [26]. The majority of DKA cases occur in patients with previously diagnosed diabetes [24]. It occurs at a rate of 1-10/100 patientyears in children with established diabetes globally. The most recent rate of DKA was 4.81/100 patient-years in children with established type 1 diabetes mellitus in Germany [10]. Up to 90\% of children with type 1 DM reported one or more episodes of DKA over the last 6 months in Sub Saharan Africa. Other studies show a variation from $25-90 \%[11,27]$.

In developing countries like Ethiopia, the risk of dying from DKA is greater. Even though many patients with diabetes mellitus in Ethiopia keep dying from DKA, there is little documentation about DKA. This creates double burden of communicable and non-communicable diseases [28]. Therefore, this study aimed to determine the incidence and predictors of diabetic ketoacidosis among children with type 1 diabetes mellitus at Debremarkos and Felegehiwot referral hospitals, 2013-2017.

\section{Methods}

\section{Study design, study setting, Study period and populations}

Hospital based retrospective follow up study was done using routine hospital data at Western Amhara referral hospitals, from September 2013 to September 2017. The study was conducted at two referral hospitals in Amhara Regional State (Northwestern Amhara); Debre Markos Referral Hospital and Felegehiwot Referral Hospital. Debremarkos Referral Hospital is found in Debre Markos City administration located at 299 km Northwest of Addis Ababa. The Hospital provides service for more than 3.5 million people [29]. A database from Information Technology prepared excell sheet was seen and about 190 children with type 1 DM were registered during the follow-up period. Felegehiwot Referral Hospital is found in Bahirdar city Administration that was located 563km from Addis Ababa.The hospital served the population in the region and those from Benshangul Gumuz population

totally more than 7 million people as a referal center [30]. In pediatric outpatient department,there were 246 diabetic children (from Information Technology prepared excel) registered during the follow-up period.

\section{Sample size determination, technique and procedure}

A total of 436 children with diabetes mellitus were registered at Debremarkos and Felegehiwot referral hospitals (purposively selected) between 2013 and 2017.The list of children with established type 1 DM was obtained from diabetic follow up logbooks (outpatient and inpatient departments) in each referral hospital.The study planned to include all children's records in those referral hospitals.But there were only 393 diabetic children's records available using the inclusion criteria.

\section{Data collection instruments}

Data was collected using English version structured checklist. The checklist addressed the socio-demographic factors and clinical characteristics. It was filled by trained data collectors.

\section{Data collectors, procedure and quality control}


Two BSc nurses were recruited to participate in data collection. Two health officers were recruited for supervision. Data collectors and supervisors were trained for one day about data collection procedure and the purpose of the research. A week before the actual data collection, checklist was pretested on 22(5\%) of the diabetic children records from the same area. Amendments were done on the checklist after the pretest. On site supervision was carried out during the whole period of data collection on daily basis by the supervisor and principal investigator. At the end of each day, checklist was reviewed and crosschecked for completeness, accuracy and consistency by the supervisors and principal investigator and corrective measures was under taken. Exclusion criteria were considered.

\section{Operational Definitions}

- Established type 1 diabetes mellitus: at least with diabetic duration of one week.

- Missed insulin: any dose of daily insulin intentionally or unintentionally missed at least in the last one week of diabetes mellitus

- Diabetic duration:- after established DM, calculated from age at diagnosis and last follow up date

- Co-morbidities: diseases like burn, lipodystrophy, trauma, surgery, depression, bronchial asthma, epilepsy, down syndrome, cardiac, renal, hepatic diseases and etc. other than infection.

- Incomplete record:-if major socio-demographic characteristics like date of admission, final follow up date etc. were not recorded.

- Hyperglycemia: fasting blood sugar above $126 \mathrm{mg} / \mathrm{dL}, \mathrm{A} 1 \mathrm{C} \geq 6.5 \%$, or random glucose concentration $\geq 200$ $\mathrm{mg} / \mathrm{dL}$ in the presence of symptoms

- Fasting: no caloric intake for at least eight hours

- Diabetic ketoacidosis: criteria of Random Blood Sugar $\geq 250 \mathrm{mg} / \mathrm{dL}$ and ketonuria in Ethiopia care set up and most developing countries. But, blood $\mathrm{PH}$ value < 7.3 and hyperglycemia in most developed countries.

- Children: those who were less than 15 years old in Ethiopian care set up.

\section{Data Analysis}

Data were entered to the Epidata version 4.2 (Sweden) statistical software and further analysis were done using STATA version 14.1(College Station, Texas 77845 USA). Descriptive results were presented using frequency, percentage, mean, standard deviation, median, Interquartile range, cumulative incidence and incidence density were calculated and some of them were presented in graphs and tables. Incidence rate ratio was also calculated and reported. The analysis was started by testing the significance of the association between each predictor and the dependent variable using Bivariable Negative binomial Poisson regression analysis. Only the predictors with PValue $\leq 0.25$ with the dependent variable as per Bivariable Negative binomial Poisson regression analysis result were entered to Multivariable Negative binomial Poisson regression analysis to determine different predictors of DKA episodes. The assumption of Standard Poisson regression model (mean equals variance) was checked and there was over dispersion depicted by comparison of mean and variance of the outcome variable and confirmed by the significance of dispersion parameter. So, Negative binomial Poisson regression analysis model was used. Model fitness was checked by Pearson chi square and deviance tests. And finally Multivariable Negative binomial Poisson regression analysis results were reported using adjusted incidence rate ratios at significance level $\leq 0.05$.

\section{Results}




\section{Sociodemographic characteristics}

A total of $393(90.13 \%)$ registered patients' charts that fulfil the inclusion criteria were reviewed. Of these, almost half, 193 (49.1\%) were females. The median age of the patients was 10 (IQR:5-12) years. Slightly more than half, $224(57 \%)$ of them were residing in rural area. Nearly half, $215(54.71 \%)$ of them were given diabetic care by father and mother. The rest were given by father 54 (13.74\%), mother $61(15.52 \%)$ and siblings only 63 (16.03\%). Two hundred twenty two $(56.5 \%)$ of the study subjects had community health insurance. Regarding ethnicity almost all, $385(98 \%)$ of patients were Amhara and the rest 8 (2\%) were Gumuz (table 1).

\section{Clinical characteristics}

The mean insulin dose was $0.96 \pm 0.32$ (mean \pm SD) $\mathrm{u} / \mathrm{kg} /$ day. The mean random blood sugar level was 390.5 \pm 80.5 (mean $\pm S D$ ) $\mathrm{mg} / \mathrm{dl}$. The median frequency of visits at diabetic follow up clinic was every two months (IQR:13).

The majority, 363 (92.5\%) of diabetic children were given diabetic education. About 211 (53.7\%) of the patients were initiated on regular insulin and NPH but all the rest were on regular insulin and Lente. About 86 (22\%) of pateints missed insulin during the over all diabetic follow up. About 15 (17.7\%) of them who missed insulin didn not get insulin from hospitals because of unavailability, 15 (17.7\%) due to forgetfullness, 21 (24.7\%) due to unavailability at home and the larger group 31(36.5\%) from those who missed insulin did not have any documentation about the reason of discontinuation.Around 98 (25\%) of the total patients had experienced infection during follow up.

Those who experienced infection had pneumonia 20 (20.6\%), both pneumonia and uninary tract infection, 20 (20.6), both pneumonia and acute gastro entritus, 18 (18.6\%), AGE, 7(7.22\%), uninary tract infection only 6 (6.2\%), both uninary tract infection and acute gastro entritus, 2 (2\%) and others (Human imunodeficiency virus infection, 8 (2\%), pulmonary tuberculosis, $4(1 \%))$ which were considered as precipitants of diabetic ketoacidosis.

Fifty six patients (14\%) had chronic commorbidites; of which 17 (4.3\%) had epilepsy, 10 (2.5\%) malnutrition, 10 (2.5\%) bronchial asthma, 7 (2\%) lipodystrophy, $3(1 \%)$ history of surgery and the rest $5(2 \%)$ had anemia,congenital heart disease or peptic ulcer disease.

Three hundred ninety three patients who were followed for different periods in five years produced 605.05 personyears of observation. With in the follow up period,there were 251 DKA events producing an overall incidence rate of 41.5 per 100 person-years. The median number of DKA was 1 (IQR:0-2). A total of 251 (63.9\%) of patients had at least one or more episodes of DKA (table 2).

\section{Predictors of Diabetic ketoacidosis among children with established DM}

Bivariable Negative Binomial Poisson Regression analysis of socio-demographic and clinical variables on incidence and predictors of diabetic ketoacidosis among children with established diabetes mellitus revealed that sex, age at diagnosis, community health insurance, primary caregiver, diabetic education, insulin type, insulin dosage, omission of insulin, clinical visits and ever infection were predictors of diabetic ketoacidosis. Whereas during the Multivariable Negative binomial Poisson regression analysis, age at diagnosis, primary caregiver, community health insurance, omission of insulin, frequency of clinical visits, baseline insulin dose,baseline insulin type and diabetic education remained significant predictors of diabetic ketoacidosis among children with 
established type 1 diabetes mellitus. But, the significance of sex and ever infection was diluted in Multivariable Negative Binomial Poisson Regression analysis (table 3)..

Diabetic children who were in the age group 10-15years had 2.61 times higher (ARR: 2.61, p value $<0.001$ ) probability of developing diabetic ketoacidosis than those who were in the age group 6-10 years. Children whose primary caregivers were siblings only had $87 \%$ increased (ARR:1.87, $p$ value $<0.001$ ) rate of DKA as compared to patients whose primary care givers were father and mother living together. But, those who were given care by their father only had a $50 \%$ increased (ARR: 1.51 , p value $=0.004$ ) rate of DKA in comparison with those living with their father and mother together.

The rate of diabetic ketoacidosis was reduced by $27 \%$ (ARR; 0.73 , p value $=0.006$ ) when patients were initiated on Lente and Regular insulin as compared to patients with NPH and Regular insulin. Children at insulin dose $>1.2$ $\mathrm{U} / \mathrm{kg} /$ day were expected to have a rate 1.39 (ARR: 1.39, $\mathrm{p}$ value $=0.015$ ) times greater for DKA than those who were at $0.6-0.8 \mathrm{U} / \mathrm{kg} /$ day. The patients who were on less than $0.6 \mathrm{U} / \mathrm{kg} / \mathrm{day}$ had a $50 \%$ decreased $(A R R: 0.5, p$ value $=$ 0.034 ) risk of DKA as compared to patients started on $0.6-0.8 \mathrm{U} / \mathrm{kg} / \mathrm{day}$.

There was a $58 \%$ increased (ARR: 1.58 , p value $<0.001$ ) rate of DKA when patients missed insulin compared to those with no omission of insulin. The rate of diabetic ketoacidosis increased by 2.35 times as patients had protracted clinical visits (>5monthly) (ARR: 2.35 , $p$ value $=0.007$ ) comparing with those having less than two monthly clinical visits. Children without community health insurance had a $51 \%$ lower (ARR; $0.49, p$ value $<0.001)$ risk of DKA than children who had community health insurance. Diabetic children who did not have any diabetic education were at about $52 \%$ more (ARR: 1.52 , $p$ value $=0.011)$ rate of diabetic ketoacidosis than those who were given (table 3)..

\section{Discussion}

In children, type 1 diabetes mellitus is the most common form of diabetes [16] where diabetic ketoacidosis occurred most [4]. The current study attempted to determine the incidence and predictors of diabetic ketoacidosis among type 1 diabetic children. The current study found that the cumulative incidence and incidence density rate was $63.9 \%$ and 41.5 per 100 person-years respectively, which was consistent with many studies in sub-Saharan Africa $[11,27]$.

In other way, this finding was much higher than the findings in developed countries $[10,15,31-36]$. This might be due to difference in study period, sample size and other socio-demographic characteristics observed between the previous and our population. Moreover, currently, the diagnostics and screening ability becomes advanced than the previous that might play significant role detaction rate.

Moreover, this study found that the cumulative incidence and incidence density rate amon chldren with type 1 DM was lower than compared with findings in Tikur Anbessa Specialized hospital (74.4\%) [37] and than that of Tanzania (89.9\%) [11], Benin teaching hospital (77.1\%) [24], Romania (67\%), Taiwan (65\%) [36]. The lower cumulative incidence might be explained by the improved diabetes education and prevention programs that have been implemented over the last decades. Similarly, the variation in the cut of point for DKA might contribute for the difference $[7,12,38]$.

In other way, the cumulative incidence and incidence density rate was higher than the studies done in Saudi Arabia (33.1\%) [15], Swedish cohort study (1.4 episodes per 100 patient years [32], Hvidoere study (4/100 patient years) 
[33], United states (31.5\%) [34], Germany (4.81/100 patient-years) [10], across five nations from England, Wales, the United State, Austria, and Germany (7.1\%) [35], Systematic review in Sweden (14\%), Canada (18.6\%), Finland (22\%) and Hungary (23\%) [36]. This higher incidence density rate in the current study could be explained by the difference in economic development (well developed diabetic care setup) in those countries; the diagnostic modality was also different because DKA was diagnosed using $\mathrm{PH}$ value < 7.3; the variation of the cut off point for DKA, the difference in the age group which was considered 'children'could be much contributary for the lower incidencein those countries $[10,11,14-16,19,26]$.

The current study also explored the potential predictors for the occurrence of DKA among diabetic children. In the present study, age at diagnosis of DM was identified as a significant predictor for DKA, age group 10-15 years was highly associated with DKA, which was consistent with many studies $[10,11,14,16,17,19,20]$. Greater personal responsibility, and less parental monitoring and endocrine changes leading to insulin resistance would be responsible for poor DKA control in this age group [10,11, 19, 39].

In addition, in this study, patients who missed insulin had an increased rate of DKA as compared to those with no omission of insulin. Other studies $[9,11,16,23]$ also confirm that omission of insulin was an important predictor of DKA. Omission of insulin causes hyperglycemia, intracellular starvation leading to stimulation of counter regulatory hormones which accelerates lipolysis and ketoacidosis $[14,16,19,28,39,40]$.

DKA was significantly associated with primary caregiver other than father and mother together. Those children, who lived with their siblings only or fathers only, had increased risk of DKA. This was in line with other studies [14, 16, 19]. The reason may be parents (father and mother together) are probably more committed to their children with a chronic illness and ensure better compliance with medication. Children under care of their parents (both father and mother) also might enjoy a stable family structure that is supportive $[10,11,14,17,19]$.

Higher insulin dose administration which is greater than $1.2 \mathrm{U} / \mathrm{kg} /$ day was also increased the rate of DKA. This finding was also in good agreement with previous studies [11, 14, 19]. This seemed to be as a result of suppression of endogenous insulin which in turn decreases basal insulin [12]. But, those children on insulin dose less than 0.6 $\mathrm{U} / \mathrm{kg} /$ day was found to be protected from risk of DKA.

Consistent to the previous studies $[14,15,19]$, the current study identified the lower frequency of clinical visits to be significantly associated with risk of DKA. This was obviously related to the lack of blood sugar monitoring and professional diabetic care $[10,11,14-16,19]$.

This study could establish the risk of insulin type on the rate of DKA. Patients who were on Lente and regular insulin combination had decreased rate of DKA as compared to patients on Neutral protamine hagedorn (NPH) and regular insulin combination. Longer duration of action and the driving down of glycated hemoglobin safely as a result of Lente insulin might account for the difference [16, 39].

Community health insurance was significantly associated with rate of DKA. This was consistent with other studies $[14,15,19,20]$. Contrary to those studies,the present study showed that diabetic children with no community health insurance had decreased rate of DKA. This might be due to many children who did not have community health insurance most probably afforded to cover the expense. In addition, patients with community health insurance might not have close diabetic follow up. And the status of community based health insurance could not be revised the next year and not well documented. 
In the current study, diabetic education was significantly associated with the rate of DKA which was consistent with many studies $[10,11,14-16,19]$. Patients who did not have any diabetic education had increased rate of DKA.

\section{Strength of the Study}

As to the researcher's knowledge, it was the first study to establish the incidence and predictors of DKA among established type $1 \mathrm{DM}$ in the study areas and even in the country. It was a cohort study that can strongly suggest cause and effect relationship between variables. The study areas were wider referral hospitals with large catchment area.

\section{Limitation of the Study}

Since the study was a retrospective study, it had its own limitation associated with poor documentation. Many other socio-demographic, clinical and economic factors for DKA couldn't be assessed. There was some difficulty comparing findings due to limited data in Ethiopia and inaccessibility to other country study report. The finding was based on patient data on the card according to the physician diagnosis. Sometimes, it might lead to misdiagnosis of DKA or other precipitants or predictors. The variation in the cut off point for the diagnosis of DKA and the difference in the age group which was considered 'children' were the other challenges of the study; it might distort the result. In conclusion, this study revealed that a substantial number of patients had at least one episode of diabetic ketoacidosis and a higher rate of diabetic ketoacidosis. Age at diagnosis, primary caregiver, frequency of clinical visits, omission of insulin, baseline insulin dose, baseline insulin type, diabetic education, and community health insurance membership were identified as significant predictors of diabetic ketoacidosis. The most suffered age group was from $10-15$ years.

\section{Conclusions}

This study revealed that a substantial number of patients had at least one episode of diabetic ketoacidosis and a higher rate of diabetic ketoacidosis. Age at diagnosis, primary caregiver, frequency of clinical visits, omission of insulin, baseline insulin dose, baseline insulin type, diabetic education, and community health insurance membership were identified as significant predictors of diabetic ketoacidosis. Early identification of patients at risk for this higher incidence of diabetic ketoacidosis and intervention programs targeting these predictors should be implemented.

\section{Abbreviations}

CE: cerebral edema

DKA: Diabetic ketoacidosis

DM: Diabetes Mellitus

DMRH: Debre Markos Referral Hospital

FHRH: Felege Hiwot Referral Hospital 


\section{Declarations}

\section{Ethics approval and consent to participate}

Ethical clearance letter was obtained from the Debre Markos University, College of Health Science. Furthermore, a permission letter was obtained from each study setting (Debre Markos Referral Hospital and Felege Hiwot Referral Hospital).

\section{Consent for publication}

\section{Not applicable}

\section{Availability of data and material}

Data will be available upon request of the corresponding author.

\section{Conflict of interests}

\section{"The authors' of this reviewer declares that there is no conflict of interests"}

\section{Funding}

\section{No funding was obtained for this study}

\section{Authors' contribution}

MS: Conception of research protocol, study design, literature review, data extraction, data analysis, interpretation and drafting the manuscript. GD, TG, CT and MY: data analysis, reviewing the manuscript, data extraction and quality assessment. All authors have read, edited for language, made for the necessary revision and approved the manuscript.

\section{Acknowledgment}

First of all, we would like to express our deepest gratitude to data collectors and supervisors for their timely submission of the collected data. Our appreciation also goes to Debre Markos and Felegehiwot referral hospitals' administrative bodies that permitted us to conduct the study. Authors would also like to extend their thanks to Debre Markos University for arranging internet and library services.

\section{References}


1.Atkilt HS, Turago,Muluken Gizaw,Tegegne,Balewgizie Sileshi: Clinical Characteristics of Diabetic Ketoacidosis in Children with Newly Diagnosed Type 1 Diabetes in Addis Ababa, Ethiopia: A Cross-Sectional Study. PloS one 2017, 12(1):e0169666.

2.Morgan CL PJ, Dixon S, Currie CJ: Estimated costs of acute hospital care for people with diabetes in the United Kingdom: a routine record linkage study in a large region. Diabet Med 2010, 27:1066-1073.

3.Humayun K, Siddiqui S, Haque A: Poster Tour 1-Diabetes and Epidemiology. 2012.

4.Lone SW, Siddiqui EU, Muhammed F, Atta I, Ibrahim MN, Raza J: Frequency, clinical characteristics and outcome of diabetic ketoacidosis in children with type-1 diabetes at a tertiary care hospital. Pediatric Diabetes 2011, 12:41.

5.Mohsena M, Goto R, Mascie-Taylor: Maternal nutritional status (as measured by height, weight and BMI) in Bangladesh: trends and socio-economic association over the period 1996 to 2007. Public Health Nutrition 2016, 19(8):1438-1445.

6.Mtumwa AH, Paul E, Vuai SAH: Determinants of undernutrition among women of reproductive age in Tanzania mainland. South African Journal of Clinical Nutrition 2016, 29(2):75-81.

7.Ramirez-Rincon A, Hincapie-Garcia J, Arango CM, Aristizabal N, Castillo E, Hincapie G, Zapata E, Cuesta DP, Delgado M, Abad V et al: Clinical Outcomes After 1 Year of Augmented Insulin Pump Therapy in Patients with Diabetes in a Specialized Diabetes Center in Medellin, Colombia. Diabetes technology \& therapeutics 2016, 18(11):713-718.

8.Federation ID: Diabetes Atlas.6th ed.Brussel BE (International Diabetes Federation). 2013.

9.Abbas Ali Mansour and Muntader Abdu-Al-Kareem Abdu-Alla: Predictors of Diabetic Ketoacidosis among Patients with Type 1 Diabetes Mellitus Seen in the Emergency Unit. British Journal of Medicine \& Medical Research 2014.

10.Beate Karges JR, Paul-Martin Holterhus,Peter Beyer,Horst Seithe,Christian Vogel,Andreas Bockmann,Dirk Peters,Silvia Muther,Andreas Neu and Reinhard W Holl Hospital admission for diabetic ketoacidosis. European Journal of Endocrinology 2013:341-350.

11.EDNA S.MAJALIWA EM, KAUSHIK RAMAIYA,ROSE MPEMBENI,ANNA SANYIWA,ANGELIKA MOHN and FRANCESCO CHIARELLI: Survey on Acute and Chronic Complicationsin Children and Adolescents With Type 1 Diabetes at Muhimbili National Hospital in Dar es Salaam, Tanzania. Diabetes Care2007.

12.Fritsch M, Rosenbauer J, Schober E, Neu A, Placzek K, Holl RW: Predictors of diabetic ketoacidosis in children and adolescents with type 1 diabetes. Experience from a large multicentre database. Pediatr Diabetes 2011, 12(4 Pt 1):307-312.

13. Hekkala A KM, Veijola R: Ketoacidosis at diagnosis of type 1 diabetes in children in Northern Finland: temporary changes over 20 years. Diabetes Care 2007, 30(4):861 -866.

14.Mariam Noorani KRaKM: Glycaemic control in type 1 diabetes mellitus among children and adolescents in a resource limited setting in Dar es Salaam,Tanzania Endocrine Disorders 2016. 
15.Mohamed Hesham SAYED MAH, Khairyah ABDULWAHED,Khairya MOUSSA, Basem Salama EL-DEEK,Hala GABELand Rana RAGHEB3: Risk factors and predictors of uncontrolled hyperglycemia and diabetic ketoacidosis in children and adolescents with type 1 diabetes mellitus in Jeddah,Western Saudi Arabia. Journal of Diabetes 2014.

16.Mukama LJ MA, Nyindo M, Philemon R, Msuya L.: Improved glycemic control and acute complications among children with type 1 diabetes mellitus in Moshi, Tanzania. Pediatric Diabetes 2013, 14: 211-216.

17.Rayzel Shulman TAS, Fiona A Miller, Alice Newman,Denis Daneman,Jonathan D Wasserman,Astrid Guttmann: Low socioeconomic status is associated with adverse events in children and teens on insulin pumps under a universal access program:a population-based cohort study. BMJ Open Diabetes Research and Care 2016 2013, 4(e000239).

18.Rewers $\mathrm{M} \mathrm{CH}$, Mackenzie T et al.: Predictors of acute complications in children with type 1 diabetes. Jama 2012:2511-2518.

19.Thomas Ngwiri FW, Barbara Predieri,Paul Ngugi,and Lorenzo lughetti Glycemic Control in Kenyan Children and Adolescents with Type 1 Diabetes Mellitus. International Journal of Endocrinology 2007.

20.Usher-Smith JA TM, Ercole A, Walter FM.: Factors associated with the presence of diabetic ketoacidosis at diagnosis of diabetes in children and young adults: a systematic review. BMJ 20112011.

21.Wolfsdorf J GN, Sperling MA: Diabetic ketoacidosis in infants, children, and Adolescents Diabetes Care 2015 2006, 29.

22.Wolfsdorf JI AJ, Craig ME, Edge J, Glaser N, Jain V, Lee WW, Mungai LN RA, Sperling MA et al: Diabetic ketoacidosis and hyperglycemic hyperosmolar state. Pediatric Diabetes 2014:154-179.

23.Satti Abdulrahim Satti IYS, Ali saeed Dammas: Diabetic Ketoacidosis in children admitted to Pediatric Intensive Care Unit of King Fahad Hospital, Al-Baha, Saudi Arabia: Precipitating factors, epidemiological parameters and clinical presentation. SUDANESE JOURNAL OF PAEDIATRICS 2013 13(2).

24.Murunga A.N and Owira P.M.O: Diabetic ketoacidosis: an overlooked child killer in sub-Saharan Africa. Tropical Medicine and International Health November 2013, 18(11):1357 -1364.

25.Gyula Soltesz CP, Gisela Dahlquist: Diabetes in the Young: a Global PerspectivelDF Diabetes Atlas fourth edition. 2011.

26.Edna S. Majaliwa BEJE, Omotayo O. Adesiyun,Paul Laigong,A. Kayode Adeniran,C. Muze Kandi, Iroro Yarhere,S. Mary Limbe, Lorenzo lughetti,: Type 1 diabetes mellitus in the African population: Epidemiology and management challenges. Acta bio-medica: Atenei Parmensis 2009.

27.A. Elamin HAaBI: Clinical pattern of childhood type 1 (insulin-dependent) diabetes mellitus in the Sudan. Diabetologia 2012, 1:645-648.

28.Kebede S: HelinaBogale (BSC). ADDIS ABABA UNIVERSITY; 2014.

29.Maru Meseret AS, and Alemayehu Bekele: Incidence and Predictors of Pregnancy among Women on ART in Debre Markos Referral Hospital, Northwest Ethiopia:A Five-Year Retrospective Cohort Study. Hindawi AIDS Research 
and Treatment, 2015, Volume 2017:8.

30.Abera B, Walle F, Tewabe T, Alem A, Yessin M: ART-naive HIV patients at Feleg-Hiwot Referral Hospital Northwest, Ethiopia. Ethiopian Journal of Health Development 2010, 24(1).

31.Nam Han cho (ed.): International Diabetic federation Diabetes Atlas, International diabetes federation, 6th edition, edn; 2013.

32.Hanas R LF, Lindblad B: A 2-yr national population study of pediatric ketoacidosis in Sweden:Predisposing conditions and insulin pump use. Pediatr Diabet 2009, 10.

33.De Beaufort CE SP, Skinner CT et al.: Continuing stability of centre differences in pediatric diabetes care:Do advances in diabetes treatment improve outcome? the Hvidoere study group on childhood. Diabet Care 20072007, 30.2245-2450.

34.Dabelea D ea: For trends in the Prevalence of Ketoacidosis at Diabetes Diagnosis; the search for Diabetes in youth study official journal of American Academy of Pediatrics 2014, 133:938.

35.David M. Maahs JMH, Naomi Holman,Nicole C. Foster,Thomas M. Kapellen,Jeremy Allgrove,Desmond A. Schatz,Sabine E. Hofer,Fiona Campbell,Claudia Steigleder-Schweiger,Roy W. Beck,Justin T. Warner,and Reinhard W. Holl: Rates of Diabetic Ketoacidosis:International Comparison With 49,859 Pediatric Patients With Type 1 Diabetes From England Wales, the U.S.,Austria, and Germany. Diabetes Care 20152012, 38:1876-1882.

36.Usher-Smith JA TM, Sharp SJ,Walter FM: Variation between countries in the frequency of diabetic ketoacidosis at first presentation of type 1 diabetes in children: a systematic review Diabetologia 2012, 55.2878-2894.

37.Mulugeta Sitot Shibeshi BF, Tedla Kebede,and Birkneh Tilahun: Pediatric diabetic retinopathy:experience of a tertiary hospital in Ethiopia. BMC Res Notes, 2016, 9(116).

38.Atkilt HS, Turago MG, Tegegne BS: Clinical Characteristics of Diabetic Ketoacidosis in Children with Newly Diagnosed Type 1 Diabetes in Addis Ababa, Ethiopia: A Cross-Sectional Study. PLoS One 2017, 12(1):e0169666.

39.Behrman R E KRM, Jenson H B (ed.): Nelson Textbook of Pediatrics:Diabetes Mellitus in Children, 19th ed edn; 2011.

40.Michal Cohen SS, Nehama Zuckerman-Levin and Naim Shehadeh: Diabetic Ketoacidosis in the Pediatric Population withType 1 Diabetes. INFOTECH OPEN SCIENCE/OPEN MIND 2015.

\section{Tables}

Table 1: Socio-demographic characteristics of diabetic children with established diabetes mellitus at western Amhara referral hospitals, Northwestern Ethiopia, 2013-2017: $(n=393)$ 


\begin{tabular}{|c|c|c|c|}
\hline Socio-demographic characteristics & & Frequency & $\begin{array}{l}\text { Percent } \\
\text { (\%) }\end{array}$ \\
\hline \multirow[t]{2}{*}{ Sex } & Male & 200 & 50.89 \\
\hline & Female & 193 & 49.11 \\
\hline Age at Diagnosis of Diabetic mellitus (IQR:5-12) & $<=5$ & 105 & 26.72 \\
\hline \multirow[t]{2}{*}{ ( in years) } & $6-10$ & 162 & 41.22 \\
\hline & $10-15$ & 126 & 32.06 \\
\hline \multirow[t]{2}{*}{ Residence } & Urban & 169 & 43 \\
\hline & Rural & 224 & 57 \\
\hline \multirow[t]{5}{*}{ Primary caregiver } & Father & 54 & 13.74 \\
\hline & Mother & 61 & 15.52 \\
\hline & Father and & 215 & 54.71 \\
\hline & mother & & \\
\hline & Siblings only & 63 & 16.03 \\
\hline \multirow[t]{2}{*}{ Community health insurance } & Yes & 222 & 56.49 \\
\hline & No & 171 & 43.51 \\
\hline \multirow[t]{2}{*}{ Ethnicity } & Amhara & 385 & 98 \\
\hline & Others & 8 & 2 \\
\hline
\end{tabular}

Table 2: Clinical characteristics of diabetic children with established diabetes mellitus, at Western Amhara referral hospitals, Northwestern Ethiopia, 2013-2017 :(n=393) 


\begin{tabular}{|c|c|c|c|}
\hline \multirow[t]{2}{*}{ Patient characteristics } & & \multicolumn{2}{|c|}{ Descriptive statistics $(\mathrm{n}=393)$} \\
\hline & & Frequency & Percent (\%) \\
\hline \multirow[t]{4}{*}{ Random blood sugar level (mg/dl) } & mean $\pm S D$ & $390.5 \pm 80.5$ & \\
\hline & $250-299$ & 48 & $12.21 \%$ \\
\hline & 300-349 & 47 & $11.96 \%$ \\
\hline & $>=350$ & 298 & $75.83 \%$ \\
\hline \multirow[t]{2}{*}{ Insulin type } & Regular insulin and NPH & 211 & $53.69 \%$ \\
\hline & Lente and Regular insulin & 182 & $46.31 \%$ \\
\hline \multirow[t]{5}{*}{ Insulin dosage (U/kg/day) } & mean $\pm S D$ & $0.96 \pm 0.32$ & \\
\hline & $<0.6$ & 13 & $3.31 \%$ \\
\hline & $0.6-0.8$ & 157 & $39.95 \%$ \\
\hline & $0.8-1.2$ & 141 & $35.88 \%$ \\
\hline & $>1.2$ & 82 & $20.87 \%$ \\
\hline \multirow[t]{2}{*}{ Diabetic education } & Yes & 363 & $92.37 \%$ \\
\hline & No & 30 & $7.63 \%$ \\
\hline \multirow[t]{3}{*}{ Omission of insulin } & 0 & 306 & $78.12 \%$ \\
\hline & $1-3$ & 78 & $19.85 \%$ \\
\hline & $>3$ & 9 & $2.29 \%$ \\
\hline \multirow[t]{3}{*}{ Clinical visits (monthly) } & $<2$ & 112 & $28.50 \%$ \\
\hline & $2-5$ & 277 & $71.48 \%$ \\
\hline & $>5$ & 4 & $0.05 \%$ \\
\hline \multirow[t]{2}{*}{ Infection } & Yes & 98 & $25 \%$ \\
\hline & No & 294 & $75 \%$ \\
\hline \multirow[t]{2}{*}{ Commorbidity } & Yes & 56 & $14.25 \%$ \\
\hline & No & 337 & $85.75 \%$ \\
\hline
\end{tabular}

Table 3: Negative Binomial Poisson Regression analysis result for incidence and predictors of diabetic ketoacidosis among children with established diabetes mellitus at Western Amhara referral hospitals, Northwestern Ethiopia, 2013-2017 







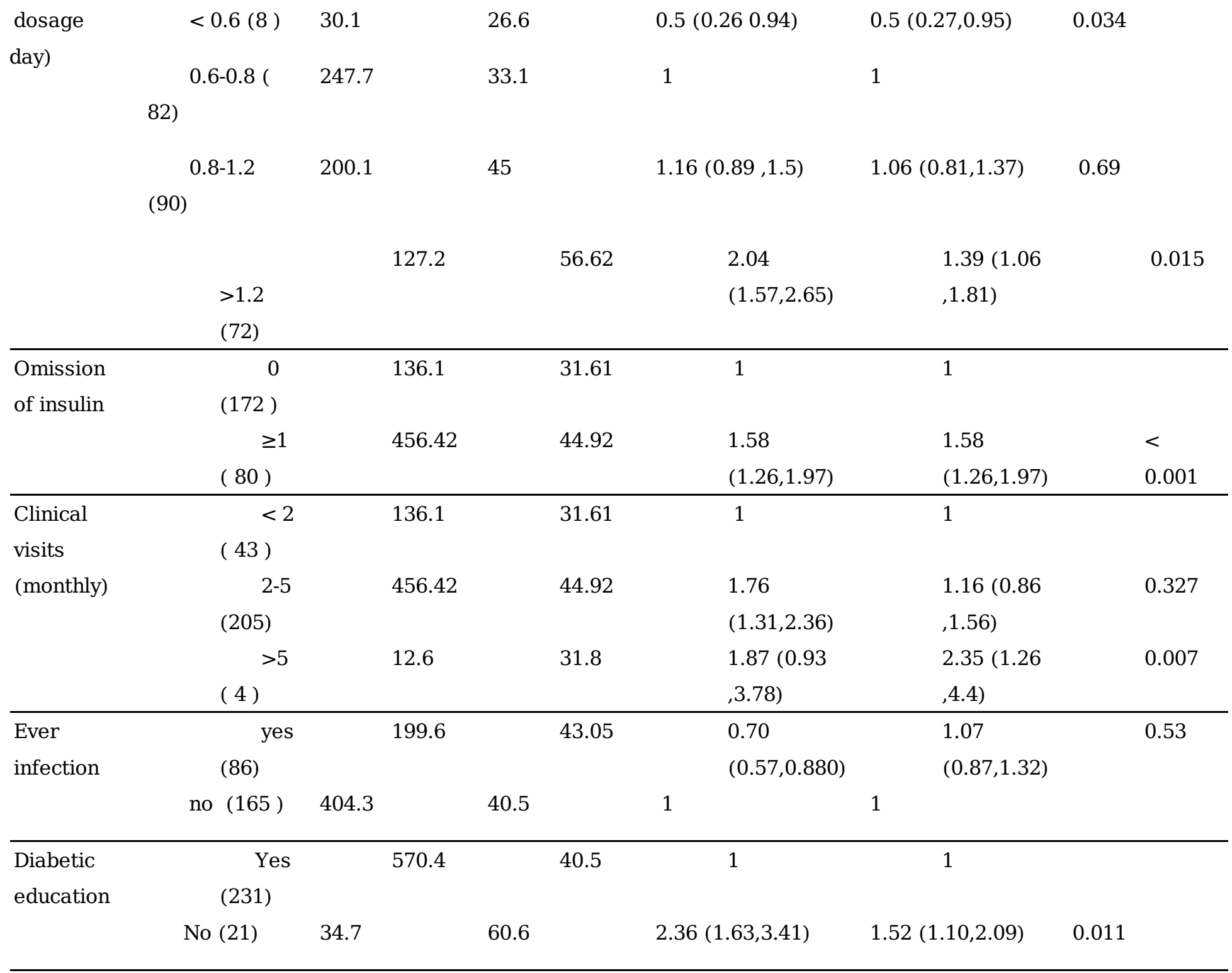

NB: In the patient characteristics (variables) column, the numbers in brackets were number of episodes (events) in each category. 